\title{
EFFECT OF PRESSURE ON PILOTED IGNITION DELAY OF PMMA
}

\author{
Sara McAllister ${ }^{a \neq}$, Janice Lai ${ }^{a}$, Sarah Scott ${ }^{a}$, Amelia Ramirez-Correa $^{a}$, Carlos Fernandez-Pello ${ }^{a}$, David \\ Urban $^{b}$, and Gary Ruff \\ ${ }^{a}$ Department of Mechanical Engineering; University of California, Berkeley; Berkeley, CA 94720, USA. \\ ${ }^{b}$ NASA John H Glenn Research Center, Cleveland, OH 44256
}

\begin{abstract}
In order to reduce the risk of decompression sickness associated with spacewalks, NASA is considering designing the next generation of exploration vehicles and habitats with a different cabin environment than used previously. The proposed environment uses a total cabin pressure of 52.7 to 58.6 $\mathrm{kPa}$ with an oxygen concentration of 30 to $34 \%$ by volume and was chosen with material flammability in mind. Because materials may burn differently under these conditions and there is little information on how this new environment affects the flammability of the materials onboard, it is important to conduct material flammability experiments at the intended exploration atmosphere. One method to evaluate material flammability is by its ease of ignition. To this end, piloted ignition delay tests were conducted in the Forced Ignition and Spread Test (FIST) apparatus subject to this new environment. In these tests, polymethylmethacylate (PMMA) was exposed to a range of oxidizer flow velocities and externally applied heat fluxes. The ultimate goal is to determine the individual effect of pressure and the combined effect of pressure and oxygen concentration on the ignition delay. Tests were conducted for a baseline case of normal pressure and oxygen concentration, low pressure $(58.6 \mathrm{kPa})$ with normal oxygen (21\%). Future work will focus on low pressure with 32\% oxygen concentration (space exploration atmosphere - SEA) conditions. It was found that reducing the pressure while keeping the oxygen concentration at $21 \%$ reduced the ignition time by $17 \%$ on average. It was also noted that the critical heat flux for ignition decreases in low-pressure conditions. Because tests conducted in standard atmospheric conditions will underpredict the flammability of materials intended for use on spacecraft, fire safety onboard at exploration atmospheres may be compromised.
\end{abstract}

\section{INTRODUCTION}

The possibility of an accidental fire onboard space vehicles and facilities has been a concern for many years [1-3]. Because these vehicles and facilities are built with a 20-year life expectancy and have flammable materials and sources of ignition onboard, the possibility of fire must be considered. The enclosed nature of space facilities, their limited egress, their dependence on electrical equipment with limited system redundancy, and the sensitivity of this equipment to soot and chlorinated products means that a fire does not have to be large to have serious consequences. Consequently, understanding material

\footnotetext{
$\ddagger$ Corresponding author:

60A Hesse Hall, Mailstop 1740

University of California at Berkeley

Berkeley, CA 94720-1740

Telephone: 510-643-5282

Fax: 510-642-1850

Email: smcallister@me.berkeley.edu
} 
flammability in the environments expected in space facilities is of utmost importance. Flammability of solid materials is typically characterized by four parameters: ignition delay or ease of ignition, flame spread rate, heat release rate, and toxicity [4]. The last three parameters are only important if the solid has already ignited, so this work will focus on the ignition delay or ease of ignition.

Significant effort has already been applied to understanding ignition delay in microgravity conditions, both theoretically and experimentally [5-9]. The conclusion drawn from each of the above studies is that in the low velocity flows commonly encountered in space-based facilities piloted ignition delay times are shorter than those in the buoyancy-induced flows of normal gravity. Additionally, the critical heat flux (CHF) for ignition in microgravity could be as little as half of the value determined in normal gravity.

The bulk of this previous work has been done using standard atmospheric conditions - 101kPa with $21 \%$ oxygen by volume. However, NASA is designing the next generation of vehicles to operate with a different cabin environment to reduce the risk of decompression sickness and the pre-breath time required for extra-vehicular activities (EVA) [10]. The proposed space exploration atmosphere (SEA) uses a total cabin pressure of 52.7 to $58.6 \mathrm{kPa}$ with an oxygen concentration of 30 to $34 \%$ by volume. It is well known that an increase in oxygen concentration can decrease the ignition delay time [11-13], but the influence of pressure is not well explored. The effect of pressure on the autoignition of polymers has been examined by several researchers, including Kishore and Sankaralingam [14], Hermance [15], Attwood and Allen [16], and Alvares [17], but the mechanisms of autoignition are different from those of piloted ignition. Cook et al [18] examined the role of pressure on piloted ignition. In this early work, the piloted ignition delay time and the ignition temperature of filter paper was measured for pressures ranging from atmospheric to $920 \mathrm{kPa}(9 \mathrm{~atm})$. The temperature of the igniter, which was in contact with the filter paper, was reported as the ignition temperature of the paper. Interestingly, the temperature of the igniter at ignition was shown to decrease as the pressure increased, but the ignition delay time showed a slight increase with pressure.

The objective of the present study is to determine the effect of lowering the atmospheric pressure on the ignition delay time of solid materials. To this end, ignition delay tests were performed using the Forced-flow Ignition and Spread Test (FIST) apparatus subject to (i) atmospheric pressure (101kPa) and oxygen concentration (21\%), and (ii) a representative pressure expected in space exploration atmospheres (SEA) (58 kPa) and atmospheric oxygen concentration (21\%). Future work will focus on the combination of low pressure and high oxygen concentration, particularly the atmosphere expected in SEA (58kPa and $\left.32 \% \mathrm{O}_{2}\right)$.

\section{DESCRIPTION OF EXPERIMENTS}

All tests were performed in the Forced-flow Ignition and flame Spread Test (FIST) apparatus developed at UC Berkeley under NASA sponsorship. A simplified schematic of the FIST tunnel is shown below in Fig. 1. The tunnel is $39.2 \mathrm{~cm}$ long in the streamwise direction, $14.9 \mathrm{~cm}$ wide, and 8.0 $\mathrm{cm}$ high. A fan at the downstream end of the tunnel induced a forced flow of 40,70 , or $100 \mathrm{~cm} / \mathrm{s}$. An infrared radiant heater was used to preheat the samples and was arranged to produce a nearly constant heat flux over the length of the sample. Tests were performed with heat fluxes of 8 to $14 \mathrm{~kW} / \mathrm{m}^{2}$. Ignition was induced with a 3-mm diameter coiled Kanthal wire mounted $10 \mathrm{~mm}$ downstream of the sample. The igniter was kept above $1000^{\circ} \mathrm{C}$ in all tests to minimize the gas-phase induction time.

The FIST flow tunnel is mounted horizontally in a containment chamber (shown in Fig. 2) that allows tests to be performed at a range of ambient pressures. The chamber pressure was monitored using a pressure transducer and was set to either atmospheric pressure or the reduced pressure planned for exploration (58.6 kPa). To make sure the chamber didn’t heat excessively during the course of a test, 
the ambient gas temperature inside the chamber was monitored with a thermocouple placed near the inlet of the tunnel.

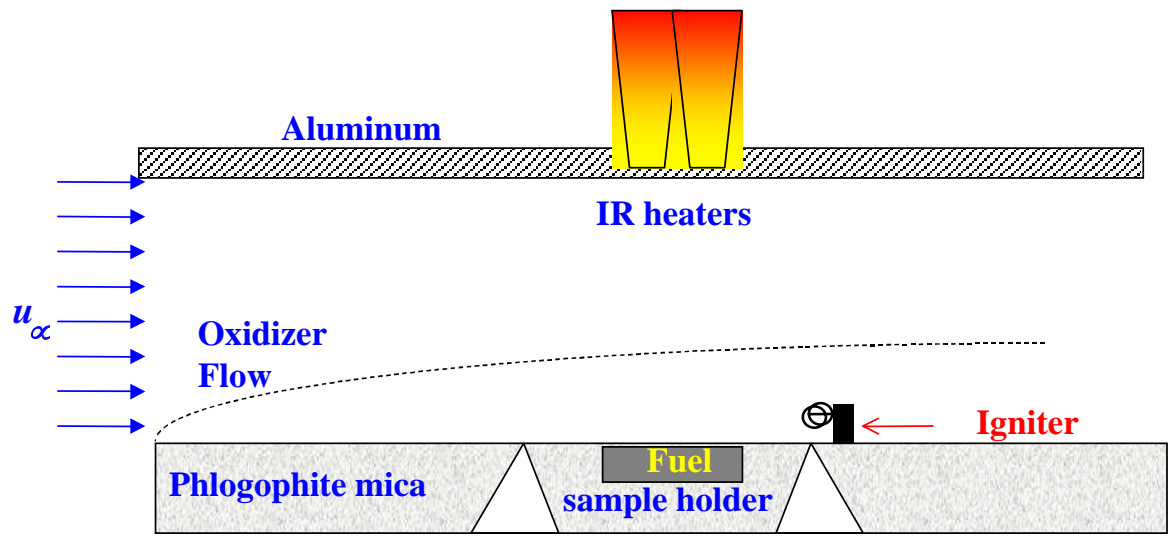

Figure 1. Simplified schematic of the FIST tunnel.

The material tested was commercially available black PMMA (Type G, Atoglas). The samples used were $30 \mathrm{~mm}$ by $30 \mathrm{~mm}$ with a thickness of $10 \mathrm{~mm}$ and were mounted so that they were flush with the surface of the tunnel. One K-type thermocouple was mounted on the top and bottom surfaces of the sample. Although care was taken to ensure that the thermocouple bead is embedded flush with the sample surface, the measured temperature should only be viewed as an approximation to the actual surface temperature due to movement of the thermocouple resulting from surface density changes. The ignition delay time was measured as the time it took the sample to ignite after the external heat flux was activated. Ignition was recorded manually based on observation but was verified by the surface temperature traces. All tests were repeated three times to provide an estimate of the experimental error.

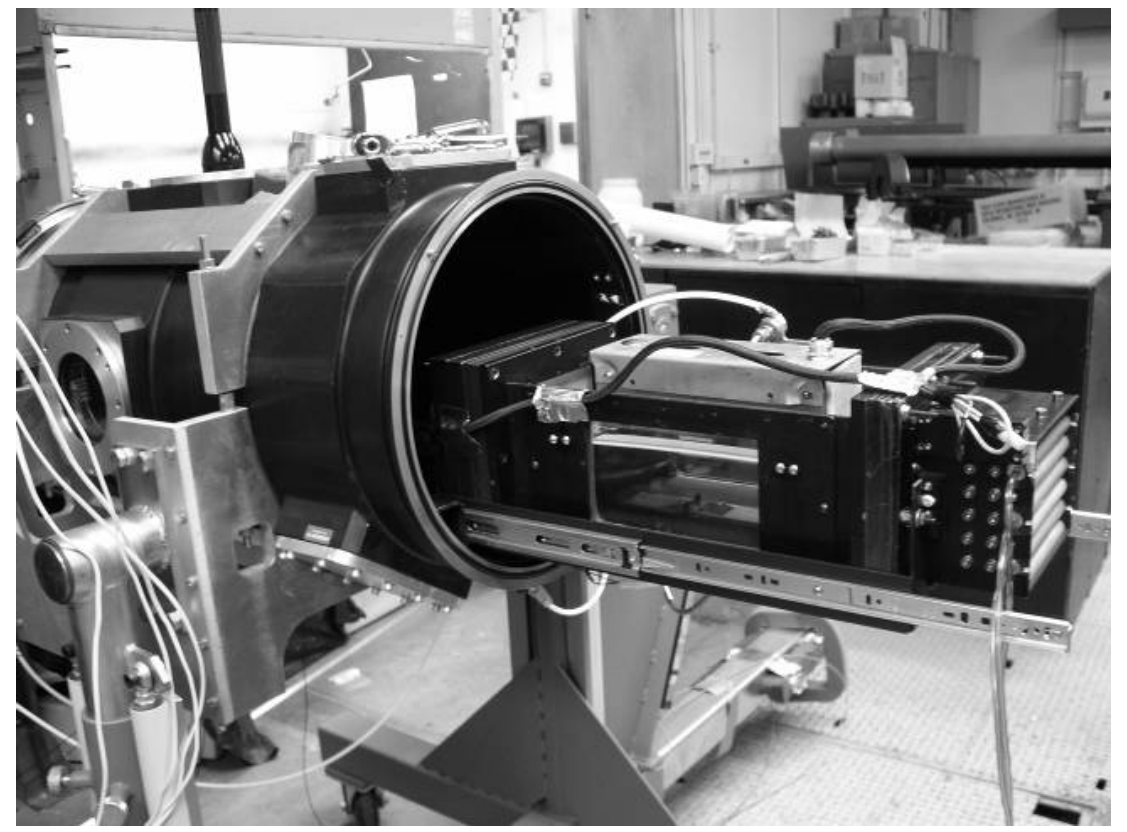

Figure 2. Photograph of the FIST tunnel in the containment chamber. 


\section{RESULTS}

The ignition delay time as a function of externally applied heat flux is shown in Fig. 3 for various oxidizer flow velocities under $58.6 \mathrm{kPa}$ and $21 \% \mathrm{O}_{2}$. The results are presented assuming thermally thick heating behavior following [19], and as discussed below. It is acknowledged that some of the ignition times are long enough that the thermal wave penetrates the entire thickness resulting in thermally intermediate behavior, but the linearity of the data suggests that the thermally thick assumption is reasonable. From the figure, it is clear that several trends seen in atmospheric conditions [11] are also seen at low pressure. The ignition delay time decreases when the externally applied heat flux increases and the flow velocity decreases. In both cases the fuel sample heats up more quickly and reaches the pyrolysis temperature sooner, decreasing the overall time required for ignition to occur.

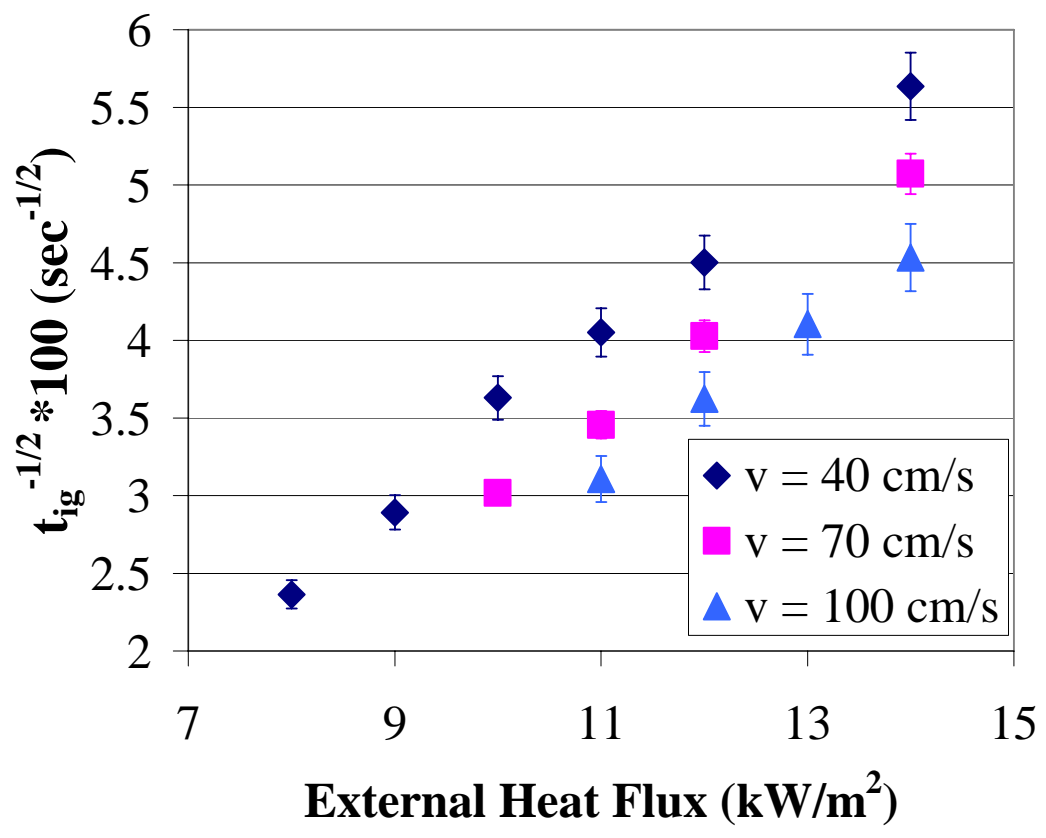

Figure 3. Ignition delay time as a function of externally applied heat flux for several oxidizer flow velocities under $58.6 \mathrm{kPa}$ and $21 \% \mathrm{O}_{2}$

Figure 4 compares the ignition delay time as a function of externally applied heat fluxes for the difference environments tested. In all plots, the piloted ignition time is shorter at low pressures. The ignition delay time decreases on average by $17 \%$ when the pressure is reduced compared to standard atmospheric conditions. If the data is extrapolated to infinitely long ignition times (when the inverse of the square root of the ignition time is equal to zero), the critical heat flux for ignition can be approximately determined [13]. From Fig. 4, it is inferred that the critical heat flux decreases when the pressure is reduced. It is important to note that the thermally thick assumption does not hold for the long delay times near the critical heat flux. The heating behavior more closely follows that of a thermally thin solid, thus the critical heat flux values determined by extending the straight-line trend based on the thermally thick assumption will be lower than the actual values, but the relation between them will stay the same. 


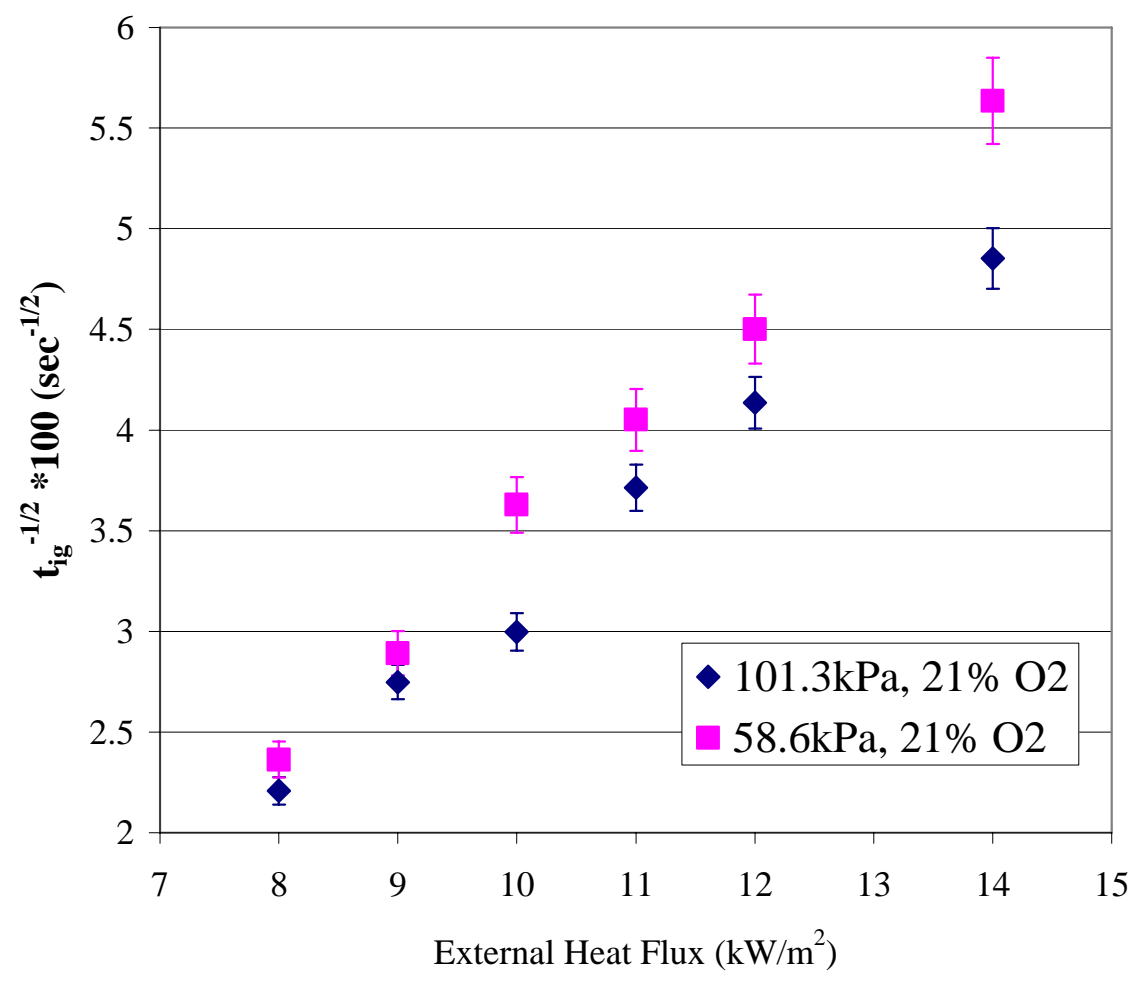

(a)

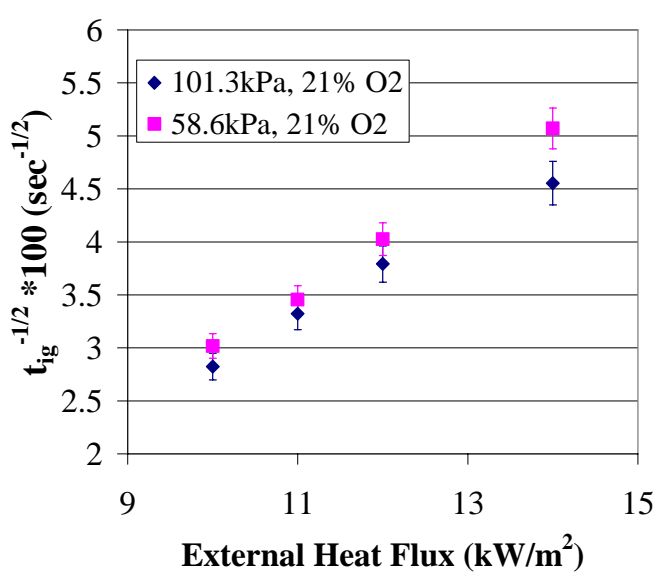

(b)

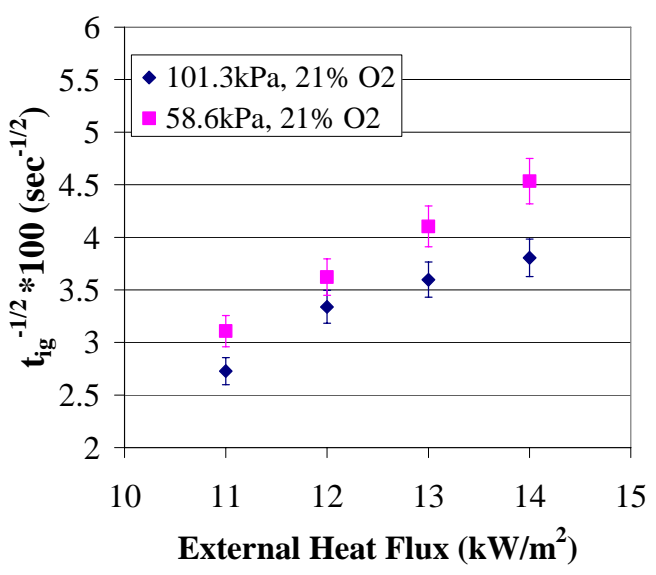

(c)

Figure 4. Ignition delay time as a function of externally applied heat flux for an oxidizer flow velocity of (a) $40 \mathrm{~cm} / \mathrm{s}$, (b) $70 \mathrm{~cm} / \mathrm{s}$, and (c) $100 \mathrm{~cm} / \mathrm{s}$.

\section{DISCUSSION}

The ignition of a solid can be viewed as a series of three events $[19,20]$. In the first, the solid must be heated to a high enough temperature for pyrolysis to occur. Once the pyrolysis gases are produced, they must mix with oxidizer to form a combustible mixture. A gas phase induction process must then occur for thermal runaway to ignition. This three-step process results in three characteristic times that, 
when combined, equal the total ignition delay time: a pyrolysis or solid heating time, a mixing time, and an induction or chemistry time. In piloted ignition, the igniter is typically very hot $\left(>1000^{\circ} \mathrm{C}\right)$, essentially removing the chemistry time as a factor [19], particularly under elevated oxygen conditions. Even when pure diffusion across the boundary layer is assumed to be the mixing mechanism, this characteristic time is still only on the order of a few seconds [19]. By comparison, the solid heating time is typically on the order of minutes, so most analytical models for solid ignition assume that the ignition time is equal to the solid heating time $[13,19,20]$.

Though the analysis seems straightforward, there is still some debate about the criterion to use for ignition. There are two main possibilities: that the solid must be heated to the ignition temperature or that the solid must be heated so that it generates the critical pyrolysis mass flux rate. If a surface temperature at ignition is assumed as the ignition criterion, an analytical expression for the ignition delay time can be easily generated using a relation for the solid heating time, such as the one by [19]. Following the thermally thick assumption, if the solid is treated as a semi-infinite solid, an order-ofmagnitude estimate of the time to ignition can be calculated as $t_{i g}^{-1 / 2} \propto \dot{q}_{e}^{\prime \prime}-h_{e f f}\left(T_{i g}-T_{\infty}\right)$, where $\dot{q}_{e}^{\prime \prime}$ is the externally applied heat flux and $h_{\text {eff }}$ is the effective heat transfer coefficient that includes convection and radiation losses. It is this relation that justifies presenting the data in terms of the ignition time to the negative one-half power, as in Figs. 3 and 4. However, the surface temperature at ignition is an empirical quantity that cannot be determined from material properties for different environmental conditions. The latter criterion, the critical pyrolysis mass flux rate, is a more physically correct criterion [21] and will therefore be the basis of our further discussion.

Piloted solid ignition occurs when sufficient pyrolysis gasses are produced so that the mixture at the igniter is at the lean flammability limit. Once the mixture near the igniter has ignited, a premixed flame may propagate back towards the solid. In order to initiate sustained burning, enough pyrolysis gases must be generated at the surface so that the temperature of the approaching flame is great enough that the heat losses to the solid do not extinguish the flame. If this is the case, a diffusion flame will become anchored at the surface. In other words, there is a critical mass flow rate of pyrolysis gases from the solid in order for sustained burning to occur [21, 22, 23].

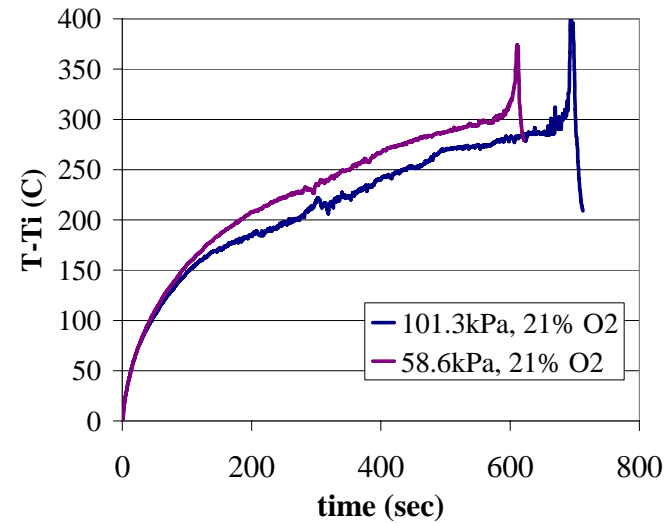

(a)

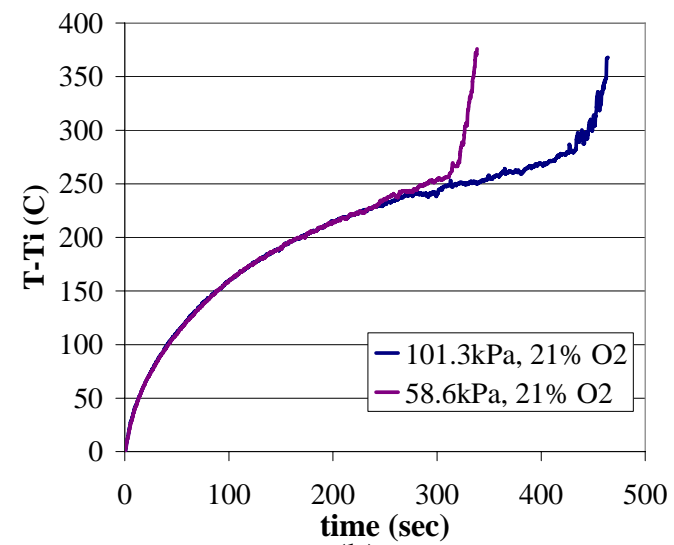

(b)

Figure 5. Surface temperature relative to the initial temperature $\left(\mathrm{T}_{\mathrm{i}, \text { ave }} \sim 30^{\circ} \mathrm{C}\right)$ as a function of time for a heat flux of $14 \mathrm{kw} / \mathrm{m}^{2}$ and an oxidizer flow velocity of (a) $100 \mathrm{~cm} / \mathrm{s}$ and (b) $40 \mathrm{~cm} / \mathrm{s}$. 
The above arguments can be used to explain the decrease in piloted ignition time as the pressure is decreased. Reducing the pressure affects all three stages of the ignition process. However, as argued above, the solid heating time is significantly larger than the mixing and chemistry time, so the effect of pressure on the heating time is dominant. Pressure affects the heating time through the critical mass flux. Though the oxidizer flow velocity is the same, the oxidizer mass flow rate decreases when pressure, and consequently the density, is reduced. Because the lean flammability limit generally is not a function of pressure [24], a lower fuel mass flow rate is required to reach the lean flammability limit, indicating that the critical mass flux rate from the solid should decrease. The temperature at which the critical mass flux is generated would be lower and therefore attained sooner, reducing the ignition time. This is confirmed in Fig. 5 where it is shown that ignition occurs at a lower surface temperature when the pressure is reduced.

Pressure also affects the heating time through the convection heat loss. For mixed forced and natural convection over a flat plate, the convective heat transfer coefficient can be represented as

$$
h \propto \operatorname{Re}^{1 / 2} \operatorname{Pr}^{1 / 3} \sqrt[4]{1+\frac{G r}{\operatorname{Re}^{2}} \operatorname{Pr}^{3}}
$$

where Re is the Reynolds number, $\mathrm{Pr}$ is the Prandtl number, and $\mathrm{Gr}$ is the Grashof number. For relatively high velocity flows, Eqn. 1 reduces to $h \propto \operatorname{Re}^{1 / 2} \operatorname{Pr}^{1 / 3}$. The Prandtl number is not a function of pressure but the Reynolds number is directly proportional to pressure through the density term. In the limit of pure natural convection, the relation for mixed convection heat transfer coefficient becomes

$h \propto G r^{1 / 4} \mathrm{Pr}^{1 / 4}$. If the oxidizer is assumed to be an ideal gas, the Grashof number is proportional to the pressure squared. No matter what form of convective heat transfer, the heat transfer coefficient is found to be proportional to the square root of the pressure. Thus, when the pressure is decreased, the heat transfer coefficient decreases resulting in less convective heat loss from the solid. With less heat loss from the solid, the temperature at which the critical mass flux rate occurs should be attained sooner (see the relation for ignition time above), resulting in a shorter ignition time. By comparing Figs 5a and 5b, it is apparent that this effect is more influential at higher flow velocities where the effect of heat loss from the solid is higher. For low velocity flows, the convection heat loss from the solid is minimal, so the reduction in ignition time at low pressure is influenced more by the reduction in the critical mass loss at ignition than by the decrease in convective heat losses.

The effect of pressure on the mixing time only further shortens the ignition time due to the inverse dependence of the diffusivity on pressure. At even lower pressures than that tested in this work, the chemistry time will eventually increase to the point where it becomes dominant. In order to determine this limit, further testing is needed, but it is clear that this is not the case for the conditions tested.

\section{CONCLUDING REMARKS}

The variation of the ignition delay of PMMA was assessed at low-pressure conditions using the FIST apparatus. For piloted ignition in the pressures tested, the ignition delay time was seen to decrease as the pressure decreases because of the reduction in convective heat losses from the solid and critical mass flux. It is expected that in the intended space exploration atmosphere (58.6kPa and $32 \% \mathrm{O} 2)$, the ignition delay time will to decrease even further due to the effect of oxygen concentration on the pyrolysis rate. If the trends noted by other researchers apply, the ignition delay time in microgravity, low-flow conditions can be even shorter, resulting in an increase in ignition hazard onboard. Additionally, the critical heat flux for ignition was also shown to decrease in low pressure environments, adding to the hazard. 
It is probable that if the pressure is reduced further, there exists a critical pressure below which the ignition delay time will increase again and the solid will eventually fail to ignite due to chemical kinetic effects. Similarly if the oxygen concentration is reduced below that of air the ignition delay will increase and eventually ignition will not occur [11]. Further experiments are needed to completely explore the effect of pressure on piloted ignition and to determine this critical pressure.

\section{ACKNOWLEDGEMENTS}

This work was supported by NASA grant NNC-05GA02G. The authors would like to thank Chris Lautenberger for his insightful discussions and input.

\section{REFERENCES}

1. Palmer, H., “Closing Remarks,” International Microgravity Combustion Workshop, NASA, Jan. 1987.

2. Faeth, G., “Closing Remarks,” Space Station Freedom Modular Combustion Facility Assessment Workshop, NASA, May 1989.

3. Friedman, R., "Risk and Issues in Fire Safety on the Space Station,” NASA TM 106403, 1994.

4. Lautenberger, C., Torero, J., and Fernandez-Pello, C., "Understanding Materials Flammability," Flammability Testing of Materials used in Construction, Transport, and Mining. Ed Vivek B Apte, CRC, 2006.

5. Zhou, Y.Y., Walther, D.C., Fernandez-Pello, A.C., Torero, J.L., and Ross, H.D. "Theoretical Prediction of Piloted Ignition of Polymeric Fuels in Microgravity at Low Velocity Flows,” Microgravity Science and Technology, v 14, n 1, 2003, p 44-50.

6. Lautenberger, C., Zhou, Y.Y., and Fernandez-Pello, A.C. "Numerical modeling of convective effects on piloted ignition of composite materials," Combustion Science and Technology, v 177, n 5-6, May/June, 2005, p 1231-1252.

7. Nakamura, Y., Yamashita, H., Takeno, T., and Kushida, G. "Effects of Gravity and Ambient Oxygen on a Gas-Phase Ignition Over a Heated Solid Fuel,” Combustion and Flame, 120: 34-48 (2000).

8. Rolson, M., Olenick, S., Zhou, Y., Walther, D., Torero, J., Fernandez-Pello, C., and Ross, H., "Microgravity Ignition Delay of Solid Fuels in Low-Velocity Flows,” AIAA Journal, v 39, n 12, December, 2001, p 2336-2342.

9. Olson, S. L., Kashiwagi, T., Fujita, O., Kikuchi, M., and Ito, K., “Experimental Observations of Spot Radiative Ignition and Subsequent Three-Dimensional Flame Spread over Thin Cellulose Fuels,” Combust. Flame 125:852 (2001).

10. Lange, K., A. Perka, B. Duffield, and F. Jeng. Bounding the Spacecraft Design Space for Future Exploration Missions, NASA/CR-2005-213689, NASA Johnson Spaceflight Center, Houston, Texas, June 2005.

11. Cordova, J.L., Walther, D.C., Torero, J.L., and Fernandez-Pello, A.C. “Oxidizer Flow Effects on the Flammability of Solid Combustibles," Combustion Science and Technology, 164:1, 253-278 (2001).

12. Atreya, A., Abu-Zaid, M. “Effect of Environmental Variables on Piloted Ignition,” Fire Safety Science Proceedings of the Third International Symposium; Eds. G. Cox. Sangfroid, Elsevier Applied Science, London, 1991, p 177.

13. Babrauskas V., Ignition Handbook, Fire Science Publishers, Issaquah, WA, 2003. 
14. Kishore, K. and Sankaralingam, S. "Effect of Pressure on Polymer Ignition,” J. Fire Sciences 4:94-99 (1986).

15. Hermance, C.E. "Ignition of Polymeric Materials Stimulated by Rapid External Heating," Flammability Characteristics of Polymeric Materials, Polymer Conference Series, College of Engineering, Univ. Utah, Salt Lake City (1971).

16. Attwood, H.C., and Allen, G.R. "On the Spontaneous Ignition Temperature of Organic Materials in Oxygen,” ARC-CP-1172, Royal Aircraft Establishment, Farnborough, UK, 1971.

17. Alvares, N.J. "The Effect of Pressure on Ignition by Thermal Radiation (WSCI 66-27),” Western States Section, The Combustion Institute, 1966 Spring Meeting.

18. Cook, G.A., Meierer, R.E., and Shields, B.M. "Screening of Flame-Resistant Materials and Comparison with Helium and Nitrogen for use in Diving Atmospheres," First Annual Summary Report on Combustion Safety in Diving Atmospheres, Contract No. N00014-66-co149, Office of Naval Research, Washington, D.C., U.S. Navy, 1967.

19. Quintiere, J. G. Fundamentals of Fire Phenomena, John Wiley \& Sons, Ltd., 2006.

20. Fernandez-Pello, A.C., "The Solid Phase," Combustion Fundamentals of Fire, ed. G. Cox, Academic Press, San Diego, 1995.

21. Rich, D., Lautenberger, C., Torero, J.L., Quintiere, J.G., and Fernandez-Pello, C. "Mass Flux of Combustible Solids at Piloted Ignition," Proceedings of the Combustion Institute, Volume 31, Issue 2, January 2007, Pages 2653-2660.

22. Rasbash, DJ; Drysdale, DD; Deepak, D, "Critical heat and mass transfer at pilot ignition and extinction of a material,” Fire Safety Journal, 10:1:1-10 (1986).

23. Quintiere, J.G., and Rangwala, A.S. "A Theory for Flame Extinction Based on Flame Temperature,” Fire and Materials 2004; 28:387-402.

24. Zabetakis, M.G., "Flammability Characteristics of Combustible Gases and Vapors (Bulletin 627),” Bureau of Mines, Pittsburgh (1965). 